Research Article

\title{
Removal of paraquat herbicide from water by textile coated with anionic cyclodextrin polymer
}

\author{
Jatupol Junthip ${ }^{1}$ (i) $\cdot$ Numhom Jumrernsuk $^{1} \cdot$ Prapin $_{K^{\prime}}$ Jongklaw $^{1} \cdot$ Warangkana Promma $^{2} \cdot$ Somchai Sonsupap $^{3}$
}

(c) Springer Nature Switzerland AG 2018

\begin{abstract}
The coating of anionic cyclodextrin polymer on polyethylene terephthalate (PET) textile was achieved by crosslinking between $\beta$-cyclodextrin ( $\beta-C D$ ) and citric acid (CTR) to adsorb paraquat herbicide from aqueous solution. This coating performance $\left(30 \mathrm{~min}, 170^{\circ} \mathrm{C}\right.$ ) was $22.18 \%$ of weight gain which was corresponded to $0.51 \mathrm{mmol} / \mathrm{g}$ of ion exchange capacity (IEC). Then, the samples were characterized by scanning electron microscopy (SEM), attenuated total reflection-Fourier transform infrared spectroscopy (ATR-FTIR) and thermogravimetric analysis (TGA). The appropriated pH was 6.5 and the equilibrium time was $420 \mathrm{~min}$. At $30^{\circ} \mathrm{C}$, the adsorption capacity towards paraquat (PQ) was enhanced $(4.5,18.9$ and $23.7 \mathrm{mg} / \mathrm{g})$ when the initial concentration of paraquat was increased $(10,50$ and $250 \mathrm{mg} / \mathrm{L})$. The adsorption kinetics was fitted to the pseudo-second-order model and the adsorption isotherm was suitable to Langmuir model. For the thermodynamic studies, the negative $\Delta \mathrm{G}^{\circ}$ revealed a spontaneous process, the negative $\Delta \mathrm{H}^{\circ}$ showed an exothermic process and the positive $\Delta \mathrm{S}^{\circ}$ displayed an enhanced disorder. Finally, the reusability of functionalized textile in methanol was reached $78.6 \%$ after six regeneration cycles and the stability of sample in various solvents was also studied.
\end{abstract}

Graphical abstract Anionic cyclodextrin polymer coated on PET textile issued from the crosslinking between $\beta$-cyclodextrin and citric acid was used as an efficient adsorbent for paraquat removal from aqueous solution.

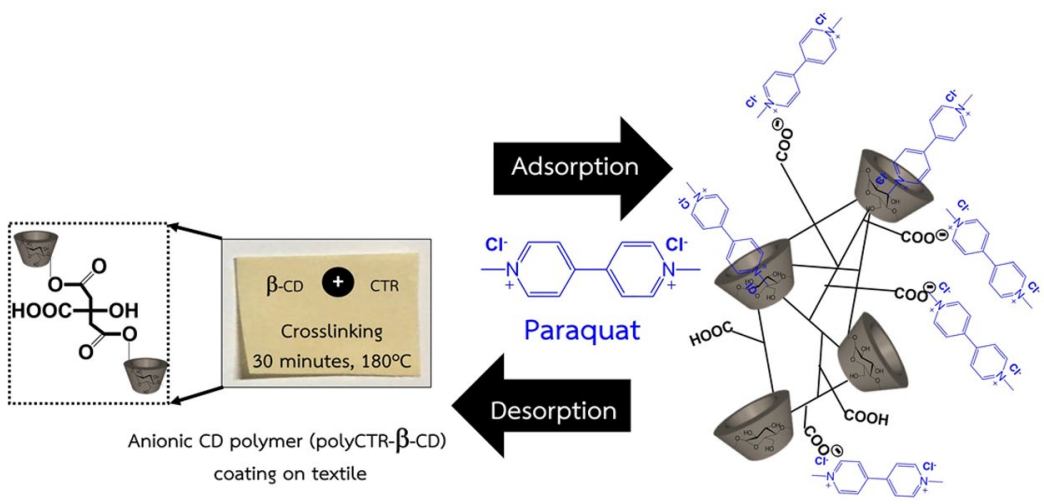

Keywords Paraquat · Adsorption · Cyclodextrin polymer $\cdot$ Functional textile $\cdot$ Water pollution

\footnotetext{
$\triangle$ Jatupol Junthip, jatupol.junthip@gmail.com ; jatupol.j@nrru.ac.th| ${ }^{1}$ Faculty of Science and Technology, Nakhon Ratchasima Rajabhat University, Nakhon Ratchasima 30000, Thailand. ${ }^{2}$ The Petroleum and Petrochemical College, Chulalongkorn University, Bangkok 10330 , Thailand. ${ }^{3}$ School of Physics, Suranaree University of Technology, Nakhon Ratchasima 30000, Thailand.
} 


\section{Introduction}

The use of pesticides in agriculture become more important because it is a rapid, efficient and easy way to reduce production costs and increase agricultural productivity. Moreover, the disadvantage of pesticides have resulted in contamination of ecosystem, accumulation of pesticides is harmful to biotic and abiotic components. Most of these chemical substances are toxic which are difficult to eliminate from the environment, especially contamination of water is a ubiquitous problem which requiring water treatment. Paraquat $(P Q)$ is a non-selective herbicide classified in bipyridinium groups. $P Q$ is a famously used pesticide in the world $[1,2]$ according to a low price, a high efficiency at low concentration and a minor accumulative effect on soil. Paraquat is employed in plantations (rice, sugar cane, coffee, beans and other crops) [3] as well as in defoliation (grass and weed) [4]. This agrochemical is very hydrosoluble $\left(620 \mathrm{~g} / \mathrm{L}\right.$ of solubility in water at $\left.25^{\circ} \mathrm{C}\right)$ because of the presence of cationic charge on the molecule, which eradicates plants by interrupting photosynthesis [1]. Nevertheless, paraquat is very dangerous for health such as dermal exposure [5], respiratory failure [6], pulmonary fibrosis [7, 8], neurotoxicity [9], damage of digestive apparatus [1] and Parkinson's disease $[10,11]$. The paraquat amount of $35 \mathrm{mg} / \mathrm{kg}$ displays lethal dose for human being owing to European standards [12]. The paraquat concentration of 0.1 and $1-3 \mu \mathrm{g} / \mathrm{L}$ exhibits respectively the maximum permissible concentration for drinking water and for surface waters [13].

Recently, various wastewater treatment processes have been reported in the literature so as to eliminate paraquat contaminated in water such as physical methods (adsorption [14], filtration $[15,16]$ and ion-exchange $[17,18])$, chemical methods (extraction [19], photocatalytic degradation $[20,21]$, oxidation $[22,23]$ and electrochemical process [24]) and biological method (fungi decomposition [25]). Among the methods mentioned above, the adsorption process demonstrates a simplicity of operation, a low-cost process and a high efficiency. Up to now, several adsorbents have been prepared to remove paraquat from aqueous solution: activated carbon [12] [26], biochar [27], membrane based on chitosan and alginate [16], activated bleaching earth [28], goethite [29,30], clays [31], rice husk [32], phillipsite-faujasite tuff [33], bentonite [34], graphene oxide nanocomposite [35], multi-walled carbon nanotubes [36], silica [37, 38], faujasite zeolite [39], iron oxide coated quartz particles [40], pillararene based porous polymer [41] and magnetic hybrid nanosorbent [42].

Cyclodextrins (CD) are cyclic oligosaccharides produced from starch by enzyme cyclodextrin glucanotransferase (CGTase), which are composed of 6, 7 and 8 units of D-glucose linked by $a-(1,4)$ glycosidic bonds (named $a$-cyclodextrin, $\beta$-cyclodextrin and $\gamma$-cyclodextrin successively). The specific and well-defined structure like bowlshaped displays a hydrophobic cavity and a hydrophilic exterior. This hydrophobic cavity provides encapsulation with suitable size and polarity of organic substances by the formation of inclusion complexes according to reversible host-guest interaction, especially inclusion with aromatic compounds. Cyclodextrin polymers are obtained from polymerization of native cyclodextrin to gain different structures which could give better encapsulation properties than pristine cyclodextrin. Moreover, the addition of charge on cyclodextrin or cyclodextrin polymers allows a good ionic interaction with the opposite charge of the guest molecule $[43,44]$. Cyclodextrin and their derivatives have fascinated important attention as selective and greater efficiency for environmental applications [45, $46]$ so as to eliminate organic substances or heavy metal [47] such as organic substances [48, 49], volatile organic compounds [50,51], dyes $[52,53]$ and pesticides $[54,55])$. Anionic cyclodextrin polymer issued from crosslinking between $\beta$-cyclodextrin as a monomer and citric acid as a crosslinker was coated on the textile surface in order to remove organic substances [56] and heavy metals [57, 58] which were contaminated in water. Nowadays, this cation-exchange textile has never reported and used for $P Q$ removal from aqueous solution.

In relevance of this work, we aimed to carry out adsorption efficiency of paraquat from water by textile coated with anionic cyclodextrin polymer using citric acid as a bridging agent with an environment-friendly process (Fig. 1). The effect of the initial concentration of paraquat, $\mathrm{pH}$ of the solution and adsorption temperature on the removal of paraquat were investigated. The appropriated models were chosen for adsorption kinetics and adsorption isotherm. Thermochemical studies were also operated at different temperatures. This adsorption technique could be an alternative way for wastewater treatment.

\section{Materials and methods}

\subsection{Materials}

PET textile was kindly given by Luckytex (Thailand) Public Company Limited. $\beta-C D$ (Acros organics), CTR monohydrate ( $\mathrm{RCl}$ labscan), sodium bicarbonate ( $\mathrm{RCl}$ labscan) sodium hypophosphite (CARLO ERBA Reagents) and paraquat dichloride hydrate (Sigma Aldrich) were gained from commercial sources. Other chemicals used in this work were analytical grade. Milli-Q ultrapure water was used for all experiments. 


\subsection{Functionalization and characterization of PET textile}

PET textile was cut off $\left(10 \times 10 \mathrm{~cm}^{2}\right)$, it was firstly washed with soxhlet apparatus $(250 \mathrm{~mL})$ using ethanol $(1 \mathrm{~h})$ and ultrapure water $(2 \mathrm{~h})$ before drying at $100{ }^{\circ} \mathrm{C}$ in hot air oven (UF10, Memmert). Cleaned textile was dipped into $100 \mathrm{~mL}$ of solution containing $10 \% \mathrm{w} / \mathrm{v}$ of $\beta-C D, 10 \% \mathrm{w} / \mathrm{v}$ of CTR and $3 \% \mathrm{w} / \mathrm{v}$ sodium hypophosphite, then it was rolled on aluminum foil by homemade roller for both sides several times before curing at $170^{\circ} \mathrm{C}$ during $30 \mathrm{~min}$ in hot air oven (UF10, Memmert). Finally, treated sample was washed again with soxhlet apparatus $(250 \mathrm{~mL})$ using ultrapure water ( $2 \mathrm{~h}$ ) so as to eliminate unreacted products before drying at $100^{\circ} \mathrm{C}$ in hot air oven (UF10, Memmert). Weight gain referring to coating yield was calculated according to this equation:

$\%$ Weight gain $=\frac{m_{f}-m_{i}}{m_{i}} \times 100$

where $m_{i}$ and $m_{f}$ relate respectively to textile weight before and after curing. Experiments were carried out in triplicate.

Functionalized textile was quantified ion exchange capacity (IEC) by pH-metric titration using calcium acetate method [59]. Textile $(0.5 \mathrm{~g})$ cut in small pieces was dipped into $50 \mathrm{~mL}$ of calcium acetate solution $(2 \% \mathrm{w} / \mathrm{v})$ for $4 \mathrm{~h}$ under agitation at $150 \mathrm{rpm}$. Textile was removed and clear solution (production of acetic acid) was titrated by $\mathrm{NaOH}$ solution $(0.05 \mathrm{M})$ employing phenolphthalein as an indicator. IEC value was expressed in $\mathrm{mmol}$ of $\mathrm{COOH}$ groups per gram of textile and it was obtained from the following equation:

$\mathrm{IEC}(\mathrm{mmol} / \mathrm{g})=\frac{\mathrm{C}_{\mathrm{NaOH}} \times \mathrm{V}_{\mathrm{NaOH}}}{\mathrm{m}} \times 100$

where $\mathrm{C}_{\mathrm{NaOH}}$ and $\mathrm{V}_{\mathrm{NaOH}}$ correspond respectively to the concentration and equivalent volume of $\mathrm{NaOH}$. The symbol $\mathrm{m}$ stands for sample weight. Experiments were performed in triplicate.

After that, functionalized textile was activated by soaking in $0.15 \mathrm{M}$ of $\mathrm{NaHCO}_{3}$ for $30 \mathrm{~min}$, washed with water until obtaining a neutral $\mathrm{pH}$ of the rinsed solution and dried at $100{ }^{\circ} \mathrm{C}$. This activation step was realized so as to convert carboxylic groups into carboxylate form without polymer hydrolysis before using this activated textile in all adsorption experiments. Experiments were performed in triplicate.

TGA (Thermogravimetric analysis) experiments were performed in an alumina pan with Thermal Analyzer-STA $449 \mathrm{~F} 3(\mathrm{NETZSCH})$ from ambient to $500^{\circ} \mathrm{C}$ with a heating rate of $10^{\circ} \mathrm{C} / \mathrm{min}$ under nitrogen gas.

ATR-FTIR (Attenuated total reflection-Fourier transform infrared spectroscopy) experiments were performed with Nicolet Nexus iS5 spectrometer (Thermo Scientific) which collected from 16 scans in $650-4000 \mathrm{~cm}^{-1}$ range with a resolution of $32 \mathrm{~cm}^{-1}$.

Samples were preliminarily coated with gold before SEM (Scanning Electron Microscopy) investigation on a

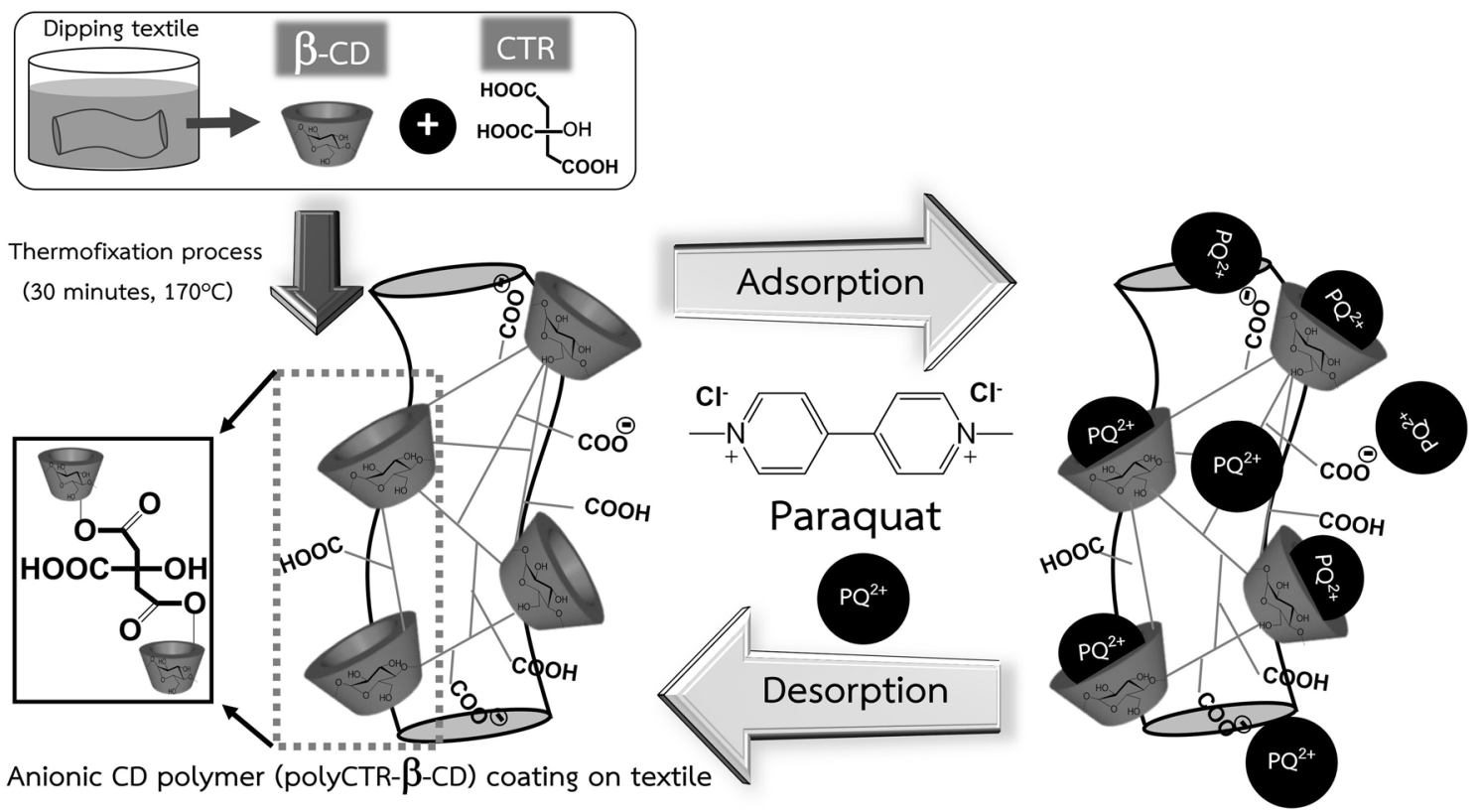

Fig. 1 Functionalization of textile with anionic cyclodextrin polymer for paraquat adsorption 
JEOL 6010 electron microscope, operating with an acceleration voltage of $15 \mathrm{kV}$.

\subsection{Adsorption experiment}

Functionalized textile $(0.1 \mathrm{~g})$ was added into $50 \mathrm{~mL}$ of $\mathrm{PQ}$ solution ( $50 \mathrm{mg} / \mathrm{L}$ of initial concentration) with different $\mathrm{pH}$ from 2 to 10 under stirring at $150 \mathrm{rpm}$ during $420 \mathrm{~min}$ at $30^{\circ} \mathrm{C}$. Solution $\mathrm{pH}$ was adjusted with $1 \mathrm{M} \mathrm{NaOH}$ and $1 \mathrm{M}$ $\mathrm{HCl}$. The measurement of $\mathrm{PQ}$ was investigated by GENESYS 10S UV-Vis spectrophotometer (Thermo Scientific) at $257 \mathrm{~nm}$ using the extinction coefficient $(\varepsilon)$ of $\mathrm{PQ}$ in water which was $0.066 \mathrm{~L} \mathrm{mg}^{-1}$ (with $\mathrm{R}^{2}=0.9994$ ). The adsorption capacity at time $\mathrm{t}(\mathrm{mg} / \mathrm{g})$ was computed by the following equation:

$\mathrm{Q}_{\mathrm{t}}=\frac{\left(\mathrm{C}_{0}-\mathrm{C}_{\mathrm{t}}\right) \mathrm{V}}{\mathrm{m}}$

where $C_{0}$ and $C_{t}$ relate successively to the initial and realtime concentration of $P Q, V$ is solution volume and $m$ is the weight of functionalized textile. Experiments were carried out in triplicate.

\subsection{Adsorption kinetics}

Functionalized textile $(0.1 \mathrm{~g})$ was put into $50 \mathrm{~mL}$ of $\mathrm{PQ}$ solution with 1050 and $250 \mathrm{mg} / \mathrm{L}$ of initial concentration with optimal $\mathrm{pH}$ at different times $(15,30,60,180,300$, $420,1440 \mathrm{~min})$ under agitation $\left(150 \mathrm{rpm}\right.$ and $\left.30^{\circ} \mathrm{C}\right)$. The quantification of $\mathrm{PQ}$ was previously mentioned in Sect. 2.3. Raw data was then fitted with two kinetics models:

Pseudo-first-order model $\ln \left(Q_{e}-Q_{t}\right)=\ln Q_{e}-k_{1} t$

Pseudo-second-order model

$$
\frac{\mathrm{t}}{\mathrm{Q}_{\mathrm{t}}}=\frac{1}{\mathrm{k}_{2} \mathrm{Q}_{\mathrm{e}}^{2}}+\frac{1}{\mathrm{Q}_{\mathrm{e}}} \mathrm{t}
$$

where $Q_{e}$ and $Q_{t}$ are the amounts of $P Q$ adsorbed (in $\mathrm{mg} / \mathrm{g}$ ) at equilibrium and at time trespectively, $\mathrm{k}_{1}(1 / \mathrm{min})$ and $\mathrm{k}_{2}(\mathrm{~g} /(\mathrm{mg} \mathrm{min}))$ are adsorption rate constant and $\mathrm{t}$ is contact time ( $\mathrm{min})$.

\subsection{Adsorption isotherm}

Functionalized textile $(0.1 \mathrm{~g})$ was put into $50 \mathrm{~mL}$ of $\mathrm{PQ}$ solution with 10,50 and $250 \mathrm{mg} / \mathrm{L}$ of initial concentration with optimal $\mathrm{pH}$ at equilibrium time under agitation (150 rpm and $30^{\circ} \mathrm{C}$ ). The quantification of PQ was previously mentioned in Sect. 2.3. Raw data was then fitted with two isotherm models:
Langmuir isotherm $\quad \frac{C_{e}}{Q_{e}}=\frac{1}{K_{L} Q_{m}}+\frac{C_{e}}{Q_{e}}$

Freundlich isotherm

$$
\ln \mathrm{Q}_{\mathrm{e}}=\ln \mathrm{K}_{\mathrm{F}}+\frac{1}{\mathrm{n}} \ln \mathrm{C}_{\mathrm{e}}
$$

where $C_{e}$ is the equilibrium concentration of $P Q, Q_{e}$ is the amount of $P Q$ adsorbed (in $\mathrm{mg} / \mathrm{g}$ ) at equilibrium, $Q_{m}$ is the theoretical maximum adsorption capacity, $\mathrm{K}_{\mathrm{L}}$ is Langmuir isotherm constant, $K_{F}$ is Freundlich constant and $1 / n$ is heterogeneity factor.

The same experiments as mentioned above were also performed at $40{ }^{\circ} \mathrm{C}$ and $50{ }^{\circ} \mathrm{C}$ in order to estimate thermodynamic parameters which indicated energy change in adsorption process according to the following equations:

$\ln \frac{Q_{e}}{C_{e}}=\frac{\Delta S^{0}}{R}-\frac{\Delta H^{0}}{R T}$ for determination of $\Delta H^{\circ}$ and $\Delta S^{\circ}$

$\Delta \mathrm{G}^{\circ}=\Delta \mathrm{H}^{\circ}-\mathrm{T} \Delta \mathrm{S}^{\circ}$ for determination of $\Delta \mathrm{G}^{\circ}$

where $C_{e}$ is equilibrium concentration of $P Q, Q_{e}$ is amount of $P Q$ adsorbed (in $\mathrm{mg} / \mathrm{g}$ ) at equilibrium, $\Delta \mathrm{H}^{\circ}$ is the standard enthalpy change in $\mathrm{kJ} / \mathrm{mol}, \Delta \mathrm{S}^{\circ}$ is the standard entropy change in $\mathrm{J} / \mathrm{K} \mathrm{mol}, \Delta \mathrm{G}^{\circ}$ is the standard free energy change in $\mathrm{kJ} / \mathrm{mol}, \mathrm{T}$ is temperature in Kelvin and $\mathrm{R}$ is gas constant (8.3124 J/K mol).

\subsection{Regeneration experiments}

Functionalized textile $(0.1 \mathrm{~g})$ was placed into $50 \mathrm{~mL}$ of $\mathrm{PQ}$ solution $(50 \mathrm{mg} / \mathrm{L}$ of initial concentration with opti$\mathrm{mal} \mathrm{pH}$ ) at equilibrium time under agitation (150 rpm and $30^{\circ} \mathrm{C}$ ). The quantification of $\mathrm{PQ}$ was previously mentioned in Sect. 2.3. Then, the adsorbent was separated and regenerated by washing in different solvents such as methanol, water and $50 \% \mathrm{v} / \mathrm{v}$ of acetic acid for $\mathrm{PQ}$ desorption. After $420 \mathrm{~min}$ of soaking, the adsorbent was cleaned with ultrapure water and reconditioned for sorption in posterior cycles.

\subsection{Adsorbent stability}

The stability of functionalized textile was performed in different solvents used in the regeneration process such as methanol, water and $50 \% \mathrm{v} / \mathrm{v}$ of acetic acid. Modified textile $(0.1 \mathrm{~g})$ was placed into $50 \mathrm{~mL}$ of each solvent under agitation ( $150 \mathrm{rpm}$ and $30^{\circ} \mathrm{C}$ ). At the desired time, this textile was removed, dried at $110^{\circ} \mathrm{C}$ for $30 \mathrm{~min}$ and 
finally weighed. The percentage of weight loss was calculated using the following equation:

$\%$ Weight loss $=\frac{m_{f}-m_{d}}{m_{f}} \times 100$

where $m_{f}$ and $m_{d}$ relate respectively to functionalized textile weight and degraded textile weight. Experiments were carried out in triplicate. Then, this textile was put back in the fresh solvent with the previous process before recalculating the weight loss.

\section{Results and discussion}

\subsection{Functionalization and characterization of adsorbent}

The coating of anionic cyclodextrin polymer on PET textile surface was achieved by crosslinking between $\beta-C D$ and CTR through esterification reaction in order to promote negative character on PET textile surface thanks to the presence of non-crosslinked carboxylic groups from CTR, which this thermofixation process was previously reported [58,59]. Coating performance was measured by weight gain of polymer $(22.18 \mathrm{wt} \%, \mathrm{~S} . \mathrm{D} .=0.89)$ and ionic exchange capacity $(0.51 \mathrm{mmol} / \mathrm{g}, \mathrm{S} . \mathrm{D} .=0.03)$. So, the loading amount of cyclodextrin polymer on the textile surface could be quantified by coating performance because the unreacted crosslinked polymer was previously removed after washing with soxhlet apparatus in order to ensure the presence of polymer on the textile surface.

As observed in Fig. 2a, the coating of anionic cyclodextrin polymer was assessed by FTIR spectroscopy with ATR mode which displayed functionalized textile comparing with untreated textile, pristine $\beta-C D$ and CTR. PET textile spectra revealed the specific bands at $1709 \mathrm{~cm}^{-1}$ corresponding to $\mathrm{C}=\mathrm{O}$ stretching of ester, at $2965 \mathrm{~cm}^{-1}$ assigning to $\mathrm{C}-\mathrm{H}$ stretching of $\mathrm{CH}_{2}$, at $1623,1573,1503$ and $1468 \mathrm{~cm}^{-1}$ attributing to stretching of benzene skeleton, at $1410 \mathrm{~cm}^{-1}$ ascribing to $\mathrm{C}-\mathrm{C}$ stretching of phenyl ring, at $1336 \mathrm{~cm}^{-1}$ allocating to wagging vibration of $\mathrm{CH}_{2}$ and at 1236 and $1089 \mathrm{~cm}^{-1}$ mentioning to $\mathrm{C}-\mathrm{O}$ asymmetric and symmetric of ester respectively. $\beta-C D$ spectra showed the characteristic peaks at $3265 \mathrm{~cm}^{-1}$ corresponding to $\mathrm{OH}$ stretching, at $2910 \mathrm{~cm}^{-1}$ assigning to $\mathrm{CH}_{2}$ stretching, at $1151 \mathrm{~cm}^{-1}$ mentioning to $\mathrm{C}-\mathrm{C}$ stretching and at $1021 \mathrm{~cm}^{-1}$ notifying to $\mathrm{C}-\mathrm{O}-\mathrm{C}$ stretching of the glycosidic bond. CTR spectra exhibited the peak of carboxylic groups at $1683-1732 \mathrm{~cm}^{-1}$ corresponding to $C=O$ stretching and at $1012 \mathrm{~cm}^{-1}$ ascribing to $C-O$ stretching. After surface modification, some absorption bands altered in the spectra of treated textile by polymer coating because of the presence of particular peaks of each component such as at $3500-3200 \mathrm{~cm}^{-1}$ ascribing to $\mathrm{O}-\mathrm{H}$ stretching of residual hydroxyls of $\beta-C D$ and at $1710 \mathrm{~cm}^{-1}$ corresponding to $C=O$ stretching of textile, CTR or anionic polymer.

Thermal stability and degradation profile of raw materials and modified textile were evaluated by TGA as illustrated in Fig. $2 \mathrm{~b}$. The first stage below $100^{\circ} \mathrm{C}$, the loss of mass was $13 \%$ and $3 \%$ for $\beta-C D$ and modified textile respectively which indicated dehydration of materials. The second stage, thermal degradation began at 135 , 260,300 and $303^{\circ} \mathrm{C}$ for CTR, modified textile, $\beta-C D$ and untreated textile successively. Apparently, modified textile had two degradation steps as a virgin textile. Functionalized textile displayed a lower thermal stability at the temperature below $360^{\circ} \mathrm{C}$ but a higher thermal stability at the temperature upper than $360^{\circ} \mathrm{C}$, compared with untreated textile. The final stage of degradation of each component was constantly seen due to a tardy decomposition of a residue which was thermally stable.

The yellow color of functionalized textile was remarked because of crosslinking with citric acid at high temperature which was different from PET virgin textile as seen in Fig. 3. The morphology of fibrous structure was observed with two magnifications. No difference could be distinguished for untreated textile (Fig. 3a) and functionalized (Fig. 3b) at $100 \times$ magnification. However, the coating of polymer on the textile surface was clearly seen at $2000 \times$ magnification as rough surface thanks to deposition of anionic polymer, comparing with virgin textile which exhibited smooth surface.

\section{2 $\mathrm{pH}$ optimization of paraquat adsorption onto the modified textile}

Preliminary studies also displayed that the adsorption of $P Q$ on non-modified textile was negligible in all experimental conditions because the maximum adsorption capacity of virgin textile reached only 0.04 (S.D. $=0.02$ ), 0.23 (S.D. $=0.05)$ and $0.56($ S.D. $=0.09)$ respectively for these initial concentrations of $P Q(10,50$ and $250 \mathrm{mg} / \mathrm{L})$. $\mathrm{pH}$ of the solution is an important factor for adsorption performance depending on the characteristics of both adsorbate (PQ) and adsorbent (modified textile). In this study, the PQ molecule which is a quaternary compound and $\mathrm{pH}$-independent. So, the essential factor is focused on the adsorbent. The initial $\mathrm{pH}$ of the $\mathrm{PQ}$ solution was evaluated in the $\mathrm{pH}$ range of 2-10 (Fig. 4b). Adsorption capacity was very poor at $\mathrm{pH}$ of 2 , adsorption process could only occur by network capture (imprisonment of PQ molecules in three-dimensional crosslinked polymer network) and inclusion complex (entrapment of $P Q$ molecules in the $\beta-C D$ cavity by host-guest interaction), as seen in 


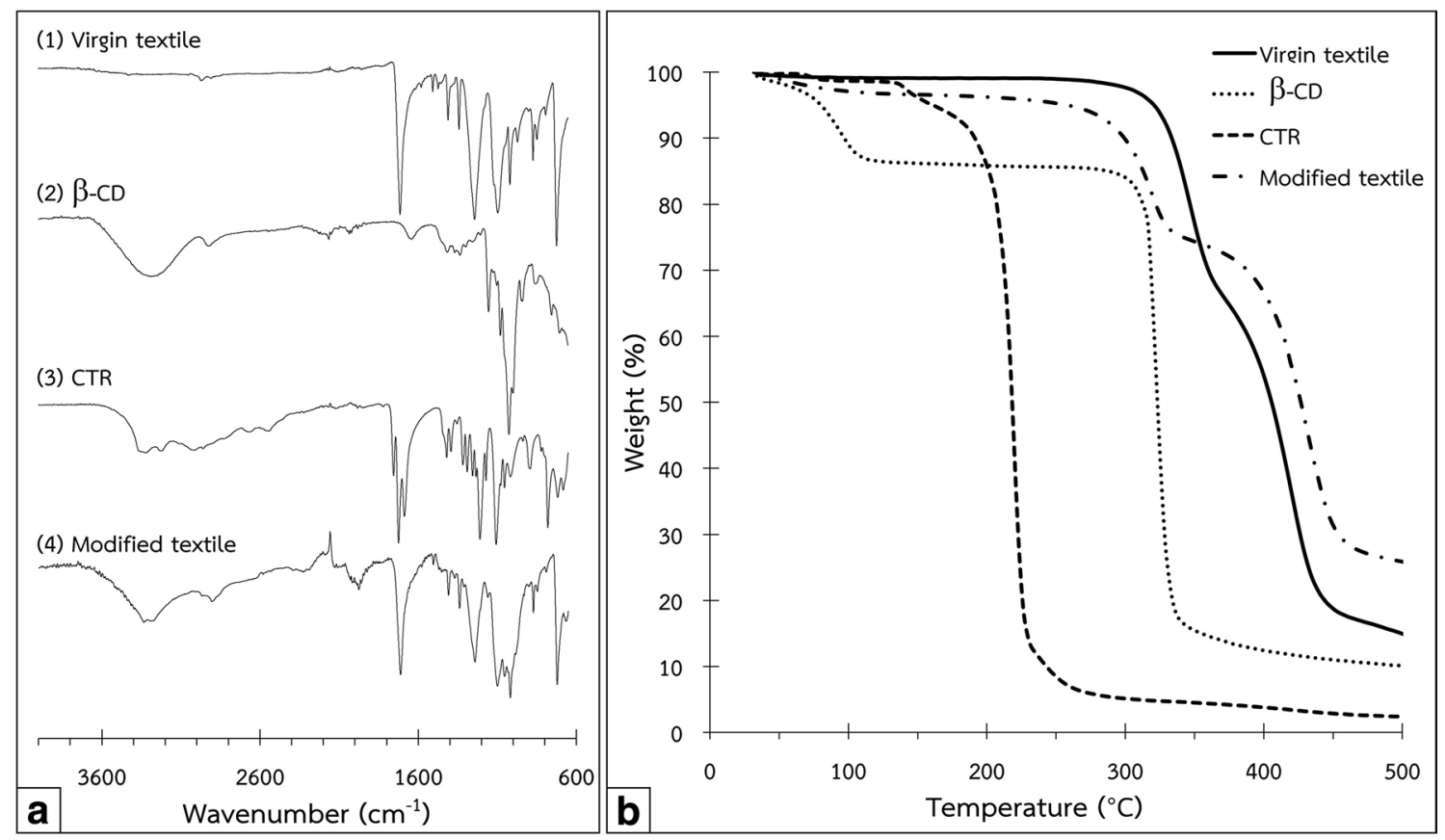

Fig. 2 ATR-FTIR spectra (a) and TGA thermograms (b) of virgin textile, $\beta-C D, C T R$ and modified textile

Fig. 4a. Indeed, modified textile showed mediocre acidity in aqueous solution at very low $\mathrm{pH}$ due to the crosslinking agent which was citric acid. Although, activated textile had already been in carboxylate form after alkaline treatment but actual functional groups could become carboxylic form at very low $\mathrm{pH}$. At this state, carboxylic groups of citric acid on the textile surface were not fully dissociated to carboxylate groups because $\mathrm{pH}$ solution was lower than the pKa of this triprotic acid (3.13, 4.76 and 6.40). Adsorption ability was very bad at low $\mathrm{pH}$ which was previously reported for a citric-crosslinked CD with sawdust [60]. So, adsorption of $\mathrm{PQ}$ was inferior.

Then, adsorption capacity increased up to $13.9 \mathrm{mg} / \mathrm{g}$ at $\mathrm{pH}$ of 3 and enhanced slightly with $\mathrm{pH}$ raise while the maximum adsorption capacity reached $(18.9 \mathrm{mg} / \mathrm{g})$ at $\mathrm{pH}$ of 6.5. In this case, adsorption procedure could happen by network capture, inclusion complex and electrostatic interaction between the cationic character of $P Q$ and anionic character of citric acid crosslinked on finished textile (Fig. 4a). Effectively, carboxylic functions were partially or totally ionized to carboxylate functions while $\mathrm{pH}$ of the solution was higher than pKa of citric acid which improved adsorption capacity between 16.5 and $18.9 \mathrm{mg} / \mathrm{g}$. Thus, adsorption capacity at this condition was enhanced thanks to electrostatic interaction which gave a supplementary force and could play an important role in the adsorption process. Thus, optimal $\mathrm{pH}$ was equal to 6.5 for following adsorption experiments as a mild condition.

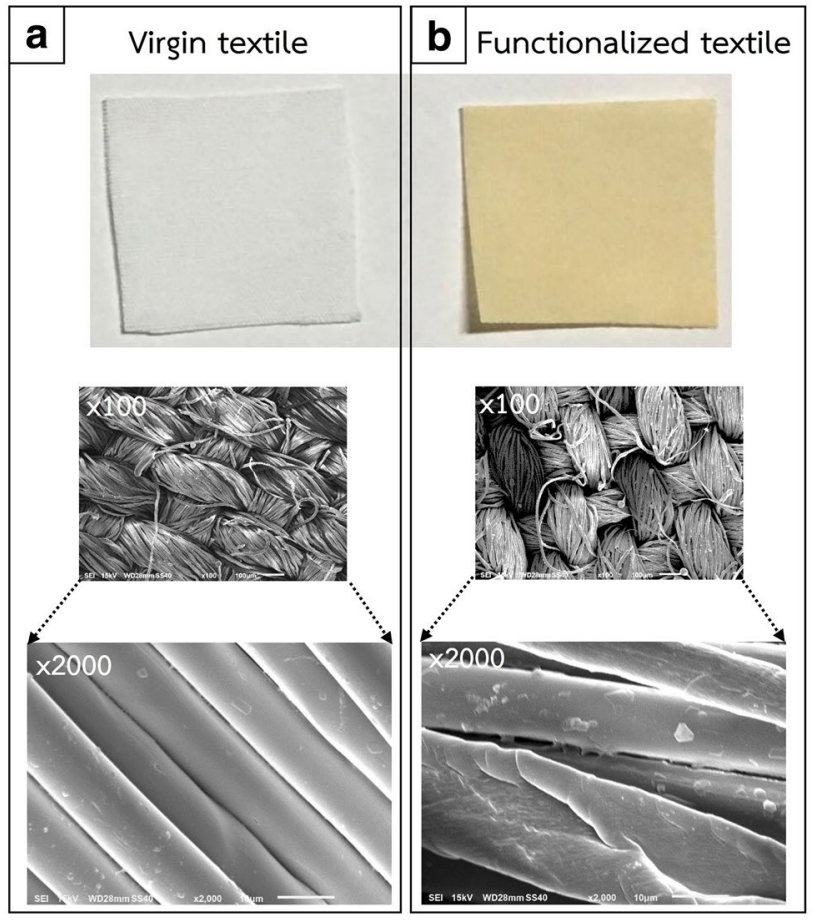

Fig. 3 Pictures and SEM images of virgin textile (a) and functionalized textile (b) with two magnifications $(\times 100$ resolution with $100 \mu \mathrm{m}$ of full scale and $\times 2000$ resolution with $10 \mu \mathrm{m}$ of full scale) 


\subsection{Adsorption kinetics}

The adsorption capacity of modified textile against contact time were carried out at various initial concentrations of PQ $\left(10,50\right.$ and $250 \mathrm{mg} / \mathrm{L}$ ) at $30^{\circ} \mathrm{C}$ (Fig. 5a). It was found that adsorption of $P Q$ enhanced rapidly for the first $60 \mathrm{~min}$, followed by a slow adsorption rate for the next $360 \mathrm{~min}$ until achieving a saturation of adsorption thanks to the replete occupation of available sites. At equilibrium time, adsorption capacity increased with the higher initial concentration of $\mathrm{PQ}$ and contact time of 420 min was selected for adsorption isotherm studies to endorse attainment of saturation state in different initial concentrations of PQ.

The pseudo-first-order model and pseudo-secondorder model were employed to further study adsorption process relating to chemical reaction, mass transfer and the adsorption order. According to fitting curves with two models (Table 1), it noted that all values of correlation coefficient $\left(R^{2}\right)$ were much higher for pseudo-secondorder model $\left(R^{2}=0.9994,0.9995\right.$ and 0.9980$)$ than pseudofirst-order model $\left(R^{2}=0.7588,0.6455\right.$ and 0.8322$)$ for these initial concentrations of $P Q(10,50$ and $250 \mathrm{mg} / \mathrm{L}$ respectively). These $\mathrm{R}^{2}$ values of pseudo-second-order model were approximately closed to 1 so as to obtain a straight line (Fig. 5b), which adsorption kinetics was described by pseudo-second-order model. Moreover, adsorption capacity at equilibrium calculated by pseudo-secondorder model $\left(Q_{e, c a l}=4.619 .3\right.$ and $\left.24.1 \mathrm{mg} / \mathrm{g}\right)$ was nearly to experimental values $\left(Q_{e, e x p}=4.5,18.9\right.$ and $\left.23.7 \mathrm{mg} / \mathrm{g}\right)$ for these initial concentrations of PQ $(10,50$ and $250 \mathrm{mg} / \mathrm{L}$ respectively).

\subsection{Adsorption isotherm}

Adsorption isotherm displays how pesticide interacts with modified textile at equilibrium state. The adsorption capacity of modified textile against concentration at equilibrium was performed at various initial concentrations of $\mathrm{PQ}$ (from 10 to $250 \mathrm{mg} / \mathrm{L}$ ) at $30^{\circ} \mathrm{C}$ (Fig. $5 \mathrm{C}$ ). Adsorption capacity at equilibrium was very fast at a low initial concentration of $\mathrm{PQ}$, but it became stable because of the unavailability of active sites on the adsorbent.

Langmuir and Freundlich isotherm models were applied to fit raw data (Fig. 5 d, e respectively). Isotherm parameters were calculated and listed in Table 2. Due to fitting curves with two models, correlation coefficient $\left(R^{2}\right)$ value was much higher for Langmuir isotherm model $\left(R^{2}=0.9990\right)$ than Freundlich isotherm model $\left(R^{2}=0.8539\right)$. This $R^{2}$ value from Langmuir isotherm model was imminent to 1 in order to obtain a linear relationship. So, Langmuir isotherm appeared a good demonstration of adsorption behavior which indicated that monolayer adsorption for $\mathrm{PQ}$ dominated on the homogenous surface of the functionalized textile. Additional information from Langmuir isotherm model, the separation factor $\left(R_{L}\right)$ revealed the tendency of the adsorption process. The $R_{L}$ values were $0.349,0.097$ and 0.021 for various initial concentrations of $P Q(10,50$ and $250 \mathrm{mg} / \mathrm{L}$ successively), which displayed a great affinity between $P Q$ molecule and treated textile because this tendency is advantageous if $0<R_{L}<1$. The functionalized textile could be used as an adsorbent for paraquat removal from aqueous solution and the maximum adsorption capacity of modified textile was $24.2 \mathrm{mg} / \mathrm{g}$. However, it showed the mediocre adsorption efficiency comparing with other adsorbents listed in Table 3.

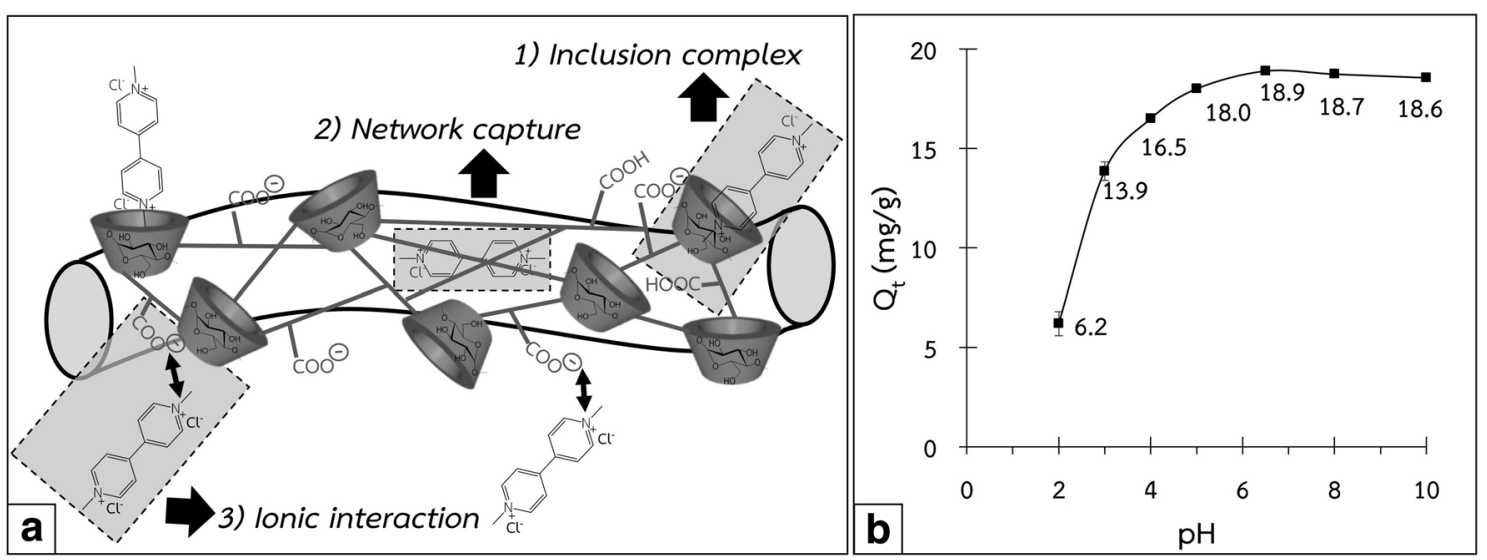

Fig. 4 a Proposed adsorption mechanism of $P Q$ adsorption on textile coated with anionic $\beta-C D$ polymer by inclusion complex, network capture and ionic interaction $\mathbf{b}$ effect of $\mathrm{pH}$ on adsorption capacity of PQ ( $2 \mathrm{~g} / \mathrm{L}$ of adsorbent dosage, $50 \mathrm{mg} / \mathrm{L}$ of $\mathrm{PQ}$ initial concentration, $420 \mathrm{~min}$ of contact time and temperature at $303 \mathrm{~K}$ ) 



Fig. 5 a Effect of contact time on adsorption capacity of $P Q \mathbf{b}$ pseudo-second-order kinetics of $\mathrm{PQ}$ adsorption $\mathbf{c}$ equilibrium isotherm $\mathbf{d}$ Langmuir isotherm e Freundlich isotherm of $P Q$ adsorp- tion for $10-250 \mathrm{mg} / \mathrm{L}$ of initial concentration of PQ $(2 \mathrm{~g} / \mathrm{L}$ of adsorbent dosage, temperature at $303 \mathrm{~K}$ and $\mathrm{pH}$ at 6.5)
Table 1 Kinetics parameters of adsorption of $\mathrm{PQ}$ on modified textile for 10,50 and $250 \mathrm{mg} / \mathrm{L}$ of initial concentration ( $2 \mathrm{~g} / \mathrm{L}$ of adsorbent dosage, temperature at $303 \mathrm{~K}$, and $\mathrm{pH}$ at 6.5)

\begin{tabular}{|c|c|c|c|c|c|c|c|}
\hline \multirow[t]{2}{*}{$\mathrm{C}_{0}(\mathrm{mg} / \mathrm{L})$} & \multirow[t]{2}{*}{$Q_{e, e x p}$} & \multicolumn{3}{|c|}{ Pseudo-first-order model } & \multicolumn{3}{|c|}{ Pseudo-second-order model } \\
\hline & & $\mathrm{R}^{2}$ & $\mathrm{Q}_{\mathrm{e}, \mathrm{cal}}$ & $\mathrm{k}_{1}$ & $\mathrm{R}^{2}$ & $\mathrm{Q}_{\mathrm{e}, \mathrm{cal}}$ & $k_{2}$ \\
\hline 10 & 4.5 & 0.7588 & 1.2 & 0.0035 & 0.9994 & 4.6 & 0.0095 \\
\hline 50 & 18.9 & 0.6455 & 8.2 & 0.0030 & 0.9995 & 19.3 & 0.0015 \\
\hline 250 & 23.7 & 0.8322 & 11.7 & 0.0023 & 0.9980 & 24.1 & 0.0008 \\
\hline
\end{tabular}

\subsection{Thermodynamic parameters}

The influence of temperature on adsorption circumstance at different temperatures $\left(30,40\right.$ and $\left.50^{\circ} \mathrm{C}\right)$ was studied as shown in Fig. 6. The fitted curve of $Q_{e} / C_{e}$ against $1 / T$ was executed to determine different thermodynamic parameters by Vant' Hoff equation which exhibited a straight line with a good correlation coefficient $\left(\mathrm{R}^{2}=0.9953\right)$. The standard enthalpy change $\left(\Delta \mathrm{H}^{\circ}\right)$ was $-1.0 \mathrm{~kJ} / \mathrm{mol}$, this negative sign indicated exothermic process and the reduction of adsorption capacity with temperature raised were earlier reported for paraquat adsorption $[38,61]$. Furthermore, the weak $\Delta \mathrm{H}^{\circ}\left(\Delta \mathrm{H}^{\circ}<40 \mathrm{~kJ} / \mathrm{mol}\right)$ was also described physisorption mechanism as the host-guest interaction between $\beta-C D$ and $P Q$. Herein, it was probably that inclusion complex mechanism was dominant than two others proposed mechanism because the size of $\mathrm{PQ}(13.4 \AA \times 3.6 \AA$ [62]) was suitable for CD cavity (7.8 $\AA$ of the internal cavity). By the way, the adsorption of the cationic organic compound on crosslink CD polymer was also informed about the important role of the $C D$ cavity for methylene blue entrapment [47]. The standard entropy change $\left(\Delta S^{\circ}\right)$ was $0.438 \mathrm{~J} / \mathrm{mol} \cdot \mathrm{K}$, this positive number exhibited an increase of randomness at the solid-liquid interface for $\mathrm{PQ}$ adsorption process. The standard Gibbs free energy change $\left(\Delta \mathrm{G}^{\circ}\right)$ was $-1.106,-1.111$ and $-1.115 \mathrm{~kJ} / \mathrm{mol}$ for the temperature at 30,40 and $50{ }^{\circ} \mathrm{C}$ respectively. All negative values expressed a spontaneous behavior of $\mathrm{PQ}$ adsorption. Moreover, the $\Delta G^{\circ}$ value decreased with temperature

\section{SN Applied Sciences}


Table 2 Isotherm parameters of adsorption of PQ on modified textile for 10,50 and $250 \mathrm{mg} / \mathrm{L}$ of initial concentration ( $2 \mathrm{~g} / \mathrm{L}$ of adsorbent dosage, temperature at $303 \mathrm{~K}, 420 \mathrm{~min}$ of contact time and $\mathrm{pH}$ at 6.5)

\begin{tabular}{|c|c|c|c|c|c|c|c|c|c|}
\hline \multicolumn{7}{|c|}{ Langmuir isotherm } & \multicolumn{3}{|c|}{ Freundlich isotherm } \\
\hline \multirow[t]{2}{*}{$\overline{Q_{e, e x p}}$} & \multirow[t]{2}{*}{$\mathrm{R}^{2}$} & \multirow[t]{2}{*}{$\mathrm{Q}_{\mathrm{m}}$} & \multirow[t]{2}{*}{$\mathrm{K}_{\mathrm{L}}$} & \multicolumn{3}{|l|}{$R_{L}$ when } & \multirow[t]{2}{*}{$\overline{\mathrm{R}^{2}}$} & \multirow[t]{2}{*}{$K_{f}$} & \multirow[t]{2}{*}{$1 / n$} \\
\hline & & & & $C_{0}=10 \mathrm{mg} / \mathrm{L}$ & $\mathrm{C}_{0}=50 \mathrm{mg} / \mathrm{L}$ & $\mathrm{C}_{0}=250 \mathrm{mg} / \mathrm{L}$ & & & \\
\hline 23.7 & 0.9990 & 24.2 & 0.186 & 0.349 & 0.097 & 0.021 & 0.8539 & 6.5 & 0.29 \\
\hline
\end{tabular}

Table 3 Comparison with other adsorbents described by the Langmuir isotherm for paraquat removal

\begin{tabular}{|c|c|c|c|c|}
\hline Adsorbent & Adsorption dosage & Paraquat concentration & Adsorption kinetics & $\begin{array}{l}\text { Maximum } \\
\text { adsorption } \\
\text { capacity }\end{array}$ \\
\hline $\begin{array}{l}\text { Polyester textile coated with cyclodextrin } \\
\text { polymer (this work) }\end{array}$ & $0.1 \mathrm{~g}$ in $0.05 \mathrm{~L}$ & $10-250 \mathrm{mg} / \mathrm{L}$ & Pseudo-second-order & $24.2 \mathrm{mg} / \mathrm{g}$ \\
\hline Activated carbon derived from used tires [12] & $1 \mathrm{~g}$ in $0.2 \mathrm{~L}$ & $100-1000 \mathrm{mg} / \mathrm{L}$ & Pseudo-second-order & $61.0 \mathrm{mg} / \mathrm{g}$ \\
\hline Swine-manure-derived biochar [27] & $0.3 \mathrm{~g}$ in $1 \mathrm{~L}$ & $0.5-6 \mathrm{mg} / \mathrm{L}$ & Pseudo-second-order & $14.8 \mathrm{mg} / \mathrm{g}$ \\
\hline Clays and organoclays [31] & $0.1 \mathrm{~g}$ in $0.02 \mathrm{~L}$ & $0.1-1 \mathrm{mmol} / \mathrm{L}$ & - & $0.19 \mathrm{mmol} / \mathrm{g}$ \\
\hline Rice husk silica [32] & $0.05 \mathrm{~g}$ in $0.02 \mathrm{~L}$ & $80-1000 \mathrm{mg} / \mathrm{L}$ & - & $185.2 \mathrm{mg} / \mathrm{g}$ \\
\hline Multi-walled carbon nanotubes [36] & $0.16 \mathrm{~g}$ in $0.1 \mathrm{~L}$ & $20-200 \mathrm{mg} / \mathrm{L}$ & Pseudo-second-order & $79.4 \mathrm{mg} / \mathrm{g}$ \\
\hline Pillararene porous polymers [41] & $5 \mathrm{mg}$ in $5 \mathrm{~mL}$ & $0.6-2 \mathrm{mmol} / \mathrm{L}$ & Pseudo-second-order & $209 \mathrm{mg} / \mathrm{g}$ \\
\hline Magnetic hybrid nanosorbents [42] & $2.5 \mathrm{mg}$ in $5 \mathrm{~mL}$ & $30-900 \mu \mathrm{g} / \mathrm{mL}$ & - & $242.2 \mathrm{mg} / \mathrm{g}$ \\
\hline
\end{tabular}

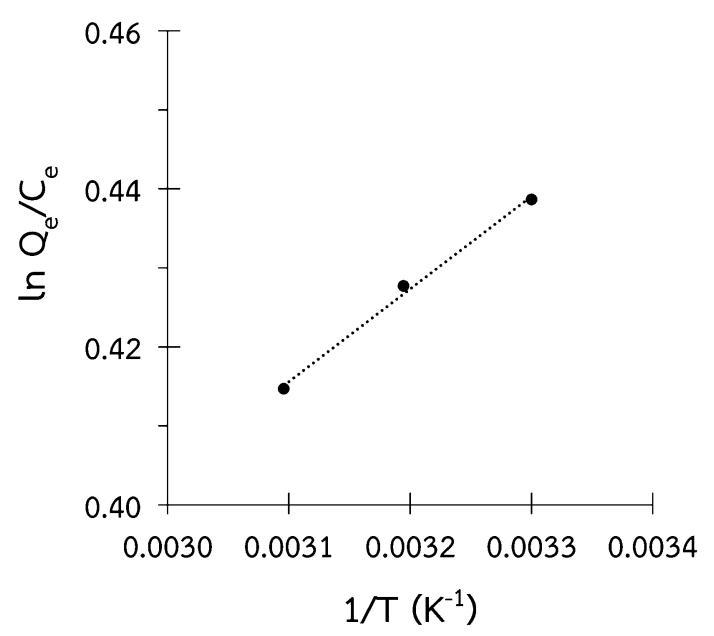

Fig. 6 Thermodynamic parameters of $\mathrm{PQ}$ adsorption at 303, 313 and $323 \mathrm{~K} \mathrm{(} 2 \mathrm{~g} / \mathrm{L}$ of Adsorbent dosage, $50 \mathrm{mg} / \mathrm{L}$ of initial concentration, $420 \mathrm{~min}$ of contact time and $\mathrm{pH}$ at 6.5)

enhanced which PQ adsorption was suitable at a lower temperature.

\subsection{Regeneration}

For economic reasons, reusability and stability of adsorbent are important criteria for the adsorption process. The appropriated solvent could play a significant role in the desorption process which is composed of the regeneration cycle. Water, $50 \% \mathrm{v} / \mathrm{v}$ of acetic acid solution and methanol were selected for $P Q$ desorption from functionalized textile. As demonstrated in Fig. 7, PQ could be easily recycled in methanol and the regeneration efficiency reached $78.6-81.7 \%$ which revealed a good stability for desorption performance. Regeneration with methanol was formerly notified a good PQ removal efficiency by pillararene based porous polymers [41]. Nevertheless, the reusability efficiency of $50 \% \mathrm{v} / \mathrm{v}$ of acetic acid solution was only $39.9 \%$ after six cycles and this efficiency of water was very poor after only one cycle.

\subsection{Adsorbent stability}

The adsorbent stability was carried out in various solvents (water, $50 \% \mathrm{v} / \mathrm{v}$ of acetic acid solution and methanol) so as to ensure its physical endurance after solvent contact in adsorption and desorption process. After $7 \mathrm{~h}$ of contact time indicated equilibrium time for adsorption and desorption process, the weight loss of functionalized textile was $9.3 \%, 8.1 \%$ and $5.1 \%$ respectively for water, $50 \% \mathrm{v} / \mathrm{v}$ of acetic acid solution and methanol (as observed in Fig. 8). However, no degradation change was observed for virgin textile. As expected, the anionic cyclodextrin polymer coated on the textile surface was hydrosoluble which degraded easily in water because the presence of ester bonds from polymer could be hydrolyzed rapidly and the hydroxyl groups from cyclodextrin molecule could create certainly 


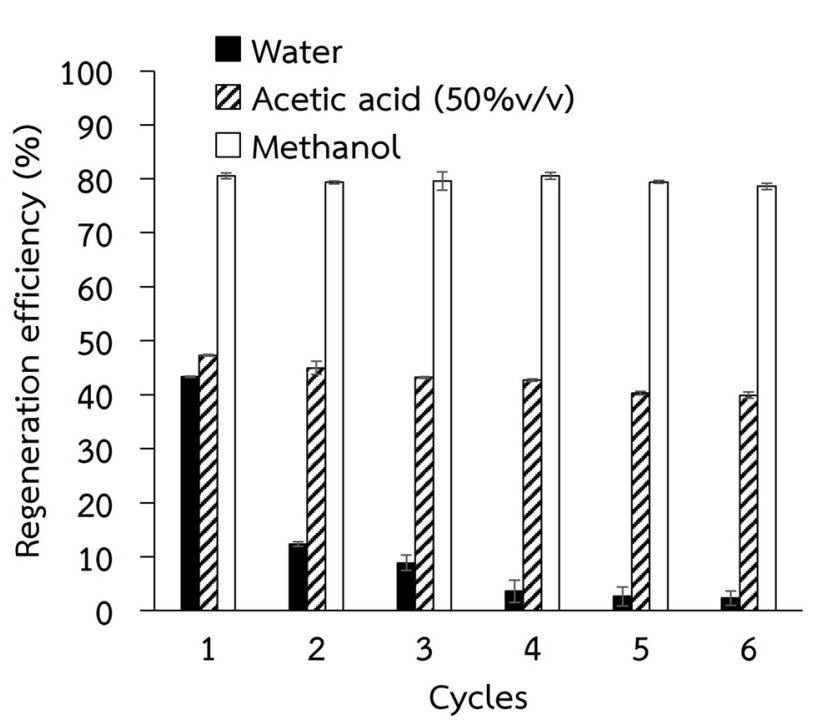

Fig. 7 Regeneration of modified textile for $P Q$ removal by using water, $50 \% \mathrm{v} / \mathrm{v}$ of acetic acid and methanol respectively. $(2 \mathrm{~g} / \mathrm{L}$ of Adsorbent dosage, $50 \mathrm{mg} / \mathrm{L}$ of initial concentration, temperature at $303 \mathrm{~K}, 420 \mathrm{~min}$ of contact time and $\mathrm{pH}$ at 6.5)

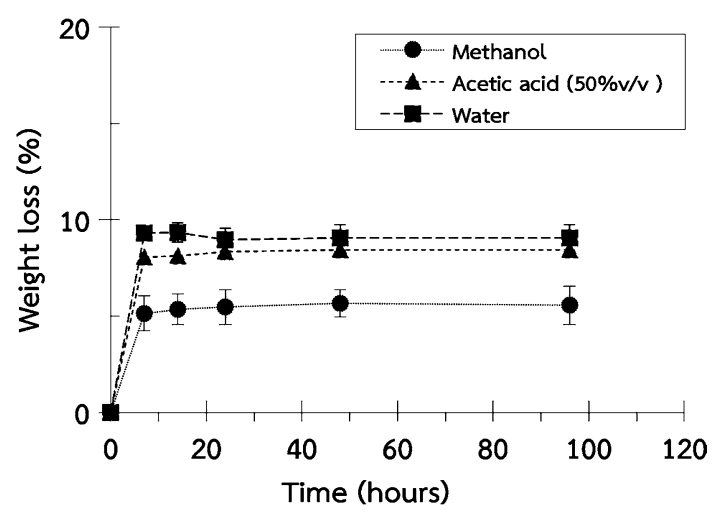

Fig. 8 Adsorbent stability in various solvents (water, $50 \% \mathrm{v} / \mathrm{v}$ of acetic acid solution and methanol)

hydrogen bonds with water molecules. This result could explain the reduction of regeneration efficiency in water for the second cycle due to the extreme loss of polymer coating on the textile surface. This kind of polymer was employed to build the multilayer assembly which showed the fast degradation rate for the multilayer assembly without thermal crosslinking [44]. Other organic solvents displayed less impact than water. By the way, no weight loss was rarely observed after the first contact with the solvent.

\section{Conclusion}

The surface modification of PET textile was firstly accomplished by crosslinking between $\beta-C D$ and CTR through the environmentally friendly process so as to promote anionic charge on the textile surface, resulting modified textile was also characterized and employed as an adsorbent for $P Q$ removal from aqueous solution. The adsorption of $\mathrm{PQ}$ on functionalized textile was better at neutral $\mathrm{pH}$ and lower temperature. Adsorption kinetics was achieved at 420 min which was suitable for pseudo-second-ordermodel and adsorption isotherm was appropriated to Langmuir model. Thermodynamic study displayed a spontaneous process, an exothermic procedure and an increased disorder. Ultimately, recyclability of functionalized textile was accomplished in methanol for $78.6 \%$ of regeneration efficiency. This kind of textile could be a promising material for cationic pesticide contaminated in water.

Acknowledgements The authors would like to thank all of the technicians for providing the facilities to accomplish experiments.

Funding This study was partially funded by Faculty of Science and Technology, Nakhon Ratchasima Rajabhat University for the first author.

\section{Compliance with ethical standards}

Conflict of interest The authors declare that they have no conflict of interest.

\section{References}

1. Nanseu-Njiki CP, Dedzo GK, Ngameni E (2010) Study of the removal of paraquat from aqueous solution by biosorption onto Ayous (Triplochiton scleroxylon) sawdust. J Hazard Mater 179:63-71

2. Mhammedi MAE, Bakasse $M$, Chtaini $A$ (2007) Electrochemical studies and square wave voltammetry of paraquat at natural phosphate modified carbon paste electrode. J Hazard Mater 145:1-7

3. Recena MCP, Caldas ED, Pires DX, Pontes ERJC (2006) Pesticides exposure in Culturama, Brazil-knowledge, attitudes, and practices. Environ Res 102:230-236

4. Núñez O, Kim JB, Moyano E, Galceran MT, Terabe S (2002) Analysis of the herbicides paraquat, diquat and difenzoquat in drinking water by micellar electrokinetic chromatography using sweeping and cation selective exhaustive injection. J Chromatogr A 961:65-75

5. Brown R, Clapp M, Dyson J, Scott D, Wheals I, Wilks M (2004) Paraquat in perspective. Outlooks Pest Manag 15:259-267

6. Dinis-Oliveira RJ, Duarte JA, Sánchez-Navarro A, Remião F, Bastos ML, Carvalho F (2008) Paraquat poisonings: mechanisms of lung toxicity, clinical features, and treatment. Crit Rev Toxicol 38:13-71 
7. Lacerda ACR, Rodrigues-Machado MDG, Mendes PL, Novaes RD, Carvalho GMC, Zin WA, Gripp F, Coimbra CC (2009) Paraquat $(\mathrm{PQ})$-induced pulmonary fibrosis increases exercise metabolic cost, reducing aerobic performance in rats. J Toxicol Sci 34:671-679

8. Cho Il Kyu, Mihye Jeong KHP, You Are-Sun, Li QX (2015) Pulmonary proteome and protein networks in response to the herbicide paraquat in rats. J Proteomics Bioinform 8:67-79

9. Smeyne RJ, Breckenridge CB, Beck M et al (2016) Assessment of the effects of MPTP and paraquat on dopaminergic neurons and microglia in the substantia nigra pars compacta of C57BL/6 mice. PLoS ONE 11:e0164094

10. Zhang X, Thompson M, Xu Y (2016) Multifactorial theory applied to the neurotoxicity of paraquat and paraquat-induced mechanisms of developing Parkinson's disease. Lab Invest 96:496-507

11. Dinis-Oliveira RJ, Remião F, Carmo H, Duarte JA, Navarro AS, Bastos ML, Carvalho F (2006) Paraquat exposure as an etiological factor of Parkinson's disease. NeuroToxicol 27:1110-1122

12. Hamadi NK, Swaminathan Sri, Chen XD (2004) Adsorption of Paraquat dichloride from aqueous solution by activated carbon derived from used tires. J Hazard Mater 112:133-141

13. Akhtar M, Hasany SM, Bhanger MI, Iqbal S (2007) Low cost sorbents for the removal of methyl parathion pesticide from aqueous solutions. Chemosphere 66:1829-1838

14. Santos MSF, Schaule G, Alves A, Madeira LM (2013) Adsorption of paraquat herbicide on deposits from drinking water networks. Chem Eng J 229:324-333

15. Burns IG, Hayes MHB, Stacey M (1973) Studies of the adsorption of paraquat on soluble humic fractions by gel filtration and ultrafiltration techniques. Pestic Sci 4:629-641

16. Cocenza DS, de Moraes MA, Beppu MM, Fraceto LF (2012) Use of biopolymeric membranes for adsorption of paraquat herbicide from water. Water Air Soil Pollut 223:3093-3104

17. Leite MP, dos Reis LGT, Robaina NF, Pacheco WF, Cassella RJ (2013) Adsorption of paraquat from aqueous medium by Amberlite $X A D-2$ and $X A D-4$ resins using dodecylsulfate as counter ion. Chem Eng J 215-216:691-698

18. Humbert H, Gallard H, Suty H, Croué J-P (2008) Natural organic matter (NOM) and pesticides removal using a combination of ion exchange resin and powdered activated carbon (PAC). Water Res 42:1635-1643

19. Zayats MF, Leschev SM, Petrashkevich NV, Zayats MA, Kadenczki L, Szitás R, Dobrik HS, Keresztény N (2013) Distribution of pesticides in $n$-hexane/water and $n$-hexane/acetonitrile systems and estimation of possibilities of their extraction isolation and preconcentration from various matrices. Anal Chim Acta 774:33-43

20. Cantavenera MJ, Catanzaro I, Loddo V, Palmisano L, Sciandrello G (2007) Photocatalytic degradation of paraquat and genotoxicity of its intermediate products. J Photochem Photobiol Chem 185:277-282

21. Sorolla MG, Dalida ML, Khemthong P, Grisdanurak N (2012) Photocatalytic degradation of paraquat using nano-sized $\mathrm{Cu}-\mathrm{TiO}_{2} /$ SBA-15 under UV and visible light. J Environ Sci 24:1125-1132

22. Santos MSF, Alves A, Madeira LM (2011) Paraquat removal from water by oxidation with Fenton's reagent. Chem Eng J 175:279-290

23. Dhaouadi A, Adhoum N (2010) Heterogeneous catalytic wet peroxide oxidation of paraquat in the presence of modified activated carbon. Appl Catal B Environ 97:227-235

24. Dhaouadi A, Adhoum N (2009) Degradation of paraquat herbicide by electrochemical advanced oxidation methods. J Electroanal Chem 637:33-42

25. Carr RJ, Bilton RF, Atkinson T (1985) Mechanism of biodegradation of paraquat by Lipomyces starkeyi. Appl Environ Microbiol 49:1290-1294
26. Nakamura T, Kawasaki N, Ogawa H, Tanada S, Kogirima M, Imaki $M$ (1999) Adsorption removal of paraquat and diquat onto activated carbon at different adsorption temperature. Toxicol Environ Chem 70:275-280

27. Tsai W-T, Chen H-R (2013) Adsorption kinetics of herbicide paraquat in aqueous solution onto a low-cost adsorbent, swinemanure-derived biochar. Int J Environ Sci Technol 10:1349-1356

28. Tsai WT, Lai CW, Hsien KJ (2004) Adsorption kinetics of herbicide paraquat from aqueous solution onto activated bleaching earth. Chemosphere 55:829-837

29. Iglesias A, López R, Gondar D, Antelo J, Fiol S, Arce F (2010) Adsorption of paraquat on goethite and humic acid-coated goethite. J Hazard Mater 183:664-668

30. Brigante M, Zanini G, Avena M (2010) Effect of humic acids on the adsorption of paraquat by goethite. J Hazard Mater 184:241-247

31. Seki Y, Yurdakoç K (2005) Paraquat adsorption onto clays and organoclays from aqueous solution. J Colloid Interface Sci 287:1-5

32. Rongchapo W, Sophiphun O, Rintramee K, Prayoonpokarach S, Wittayakun J (2013) Paraquat adsorption on porous materials synthesized from rice husk silica. Water Sci Technol 68:863-869

33. Ibrahim KM, Jbara HA (2009) Removal of paraquat from synthetic wastewater using phillipsite-faujasite tuff from Jordan. J Hazard Mater 163:82-86

34. Ait Sidhoum D, Socías-Viciana MM, Ureña-Amate MD, Derdour A, González-Pradas E, Debbagh-Boutarbouch N (2013) Removal of paraquat from water by an Algerian bentonite. Appl Clay Sci 83-84:441-448

35. Hao Y, Wang Z, Gou J, Wang Z (2015) Kinetics and thermodynamics of diquat removal from water using magnetic graphene oxide nanocomposite. Can J Chem Eng 93:1713-1720

36. Hao H, Feng JG, Liu WJ, Wu XM (2015) Removal of paraquat from aqueous solutions using multi-walled carbon nanotubes: kinetic, isotherm and thermodynamic studies. Adv Mater Res 1088:13-17

37. Barna SF, Ott EA, Nguyen TH, Shannon MA, Scheeline A (2013) Silica adsorbents and peroxide functionality for removing paraquat from wastewater. J Environ Eng 139:975-985

38. Brigante M, Schulz PC (2011) Adsorption of paraquat on mesoporous silica modified with titania: effects of $\mathrm{pH}$, ionic strength and temperature. J Colloid Interface Sci 363:355-361

39. Rongchapo W, Keawkumay C, Osakoo N, Deekamwong K, Chanlek N, Prayoonpokarach S, Wittayakun J (2017) Comprehension of paraquat adsorption on faujasite zeolite $\mathrm{X}$ and $\mathrm{Y}$ in sodium form. Adsorpt Sci Technol 36:684-693

40. Pateiro-Moure $M$, Bermúdez-Couso $A$, Fernández-Calviño $D$, Arias-Estévez M, Rial-Otero R, Simal-Gándara J (2010) Paraquat and diquat sorption on iron oxide coated quartz particles and the effect of phosphates. J Chem Eng Data 55:2668-2672

41. Lan S, Zhan S, Ding J, Ma J, Ma D (2017) Pillar[n]arene-based porous polymers for rapid pollutant removal from water. J Mater Chem A 5:2514-2518

42. Fernandes T, Soares SF, Trindade T, Daniel-da-Silva AL (2017) Magnetic hybrid nanosorbents for the uptake of paraquat from water. Nanomaterials 7:68

43. Brusseau ML, Wang X, Wang W-Z (1997) Simultaneous elution of heavy metals and organic compounds from soil by cyclodextrin. Environ Sci Technol 31:1087-1092

44. Junthip J, Tabary N, Chai F et al (2016) Layer-by-layer coating of textile with two oppositely charged cyclodextrin polyelectrolytes for extended drug delivery. J Biomed Mater Res A 104:1408-1424

45. Morin-Crini N, Crini G (2013) Environmental applications of water-insoluble $\beta$-cyclodextrin-epichlorohydrin polymers. Prog Polym Sci 38:344-368 
46. Leudjo Taka A, Pillay K, Mbianda XY (2017) Nanosponge cyclodextrin polyurethanes and their modification with nanomaterials for the removal of pollutants from waste water: a review. Carbohydr Polym 159:94-107

47. Zhao F, Repo E, Yin D, Meng Y, Jafari S, Sillanpää M (2015) EDTACross-Linked $\beta$-cyclodextrin: an environmentally friendly bifunctional adsorbent for simultaneous adsorption of metals and cationic dyes. Environ Sci Technol 49:10570-10580

48. Gong T, Zhou Y, Sun L, Liang W, Yang J, Shuang S, Dong C (2016) Effective adsorption of phenolic pollutants from water using $\beta$-cyclodextrin polymer functionalized $\mathrm{Fe}_{3} \mathrm{O}_{4}$ magnetic nanoparticles. RSC Adv 6:80955-80963

49. Li X, Zhou M, Jia J, Jia Q (2018) A water-insoluble viologen-based $\beta$-cyclodextrin polymer for selective adsorption toward anionic dyes. React Funct Polym 126:20-26

50. Alzate-Sánchez DM, Smith BJ, Alsbaiee A, Hinestroza JP, Dichtel WR (2016) Cotton fabric functionalized with a $\beta$-cyclodextrin polymer captures organic pollutants from contaminated air and water. Chem Mater 28:8340-8346

51. Celebioglu A, Sen HS, Durgun E, Uyar T (2016) Molecular entrapment of volatile organic compounds (VOCs) by electrospun cyclodextrin nanofibers. Chemosphere 144:736-744

52. Ghemati $D$, Aliouche $D(2014)$ Dye adsorption behavior of polyvinyl alcohol/glutaraldehyde/ $\beta$-cyclodextrin polymer membranes. J Appl Spectrosc 81:257-263

53. Massaro M, Colletti CG, Lazzara G, Guernelli S, Noto R, Riela S (2017) Synthesis and characterization of halloysite-cyclodextrin nanosponges for enhanced dyes adsorption. ACS Sustain Chem Eng 5:3346-3352

54. Flaherty RJ, Nshime B, DeLaMarre M, DeJong S, Scott P, Lantz AW (2013) Cyclodextrins as complexation and extraction agents for pesticides from contaminated soil. Chemosphere 91:912-920
55. Lannoy A, Bleta R, Machut-Binkowski C, Addad A, Monflier E, Ponchel A (2017) Cyclodextrin-directed synthesis of gold-modified $\mathrm{TiO}_{2}$ materials and evaluation of their photocatalytic activity in the removal of a pesticide from water: effect of porosity and particle size. ACS Sustain Chem Eng 5:3623-3630

56. Euvrard É, Morin-Crini N, Druart C, Bugnet J, Martel B, Cosentino C, Moutarlier V, Crini G (2016) Cross-linked cyclodextrinbased material for treatment of metals and organic substances present in industrial discharge waters. Beilstein J Org Chem 12:1826-1838

57. Degoutin S, Saffre C, Ruffin D, Bacquet M, Martel B (2015) Metallic pollutant removal in leachates extracted from sediment by geotextiles based on crosslinked bio-sourced polymers. Rev Sci Eau 28:43

58. Ducoroy L, Bacquet M, Martel B, Morcellet M (2008) Removal of heavy metals from aqueous media by cation exchange nonwoven PET coated with $\beta$-cyclodextrin-polycarboxylic moieties. React Funct Polym 68:594-600

59. Ducoroy L, Martel B, Bacquet M, Morcellet M (2007) Ion exchange textiles from the finishing of PET fabrics with cyclodextrins and citric acid for the sorption of metallic cations in water. J Incl Phenom Macrocycl Chem 57:271-277

60. Hu Q, Gao D-W, Pan H, Hao L, Wang P (2014) Equilibrium and kinetics of aniline adsorption onto crosslinked sawdust-cyclodextrin polymers. RSC Adv 4:40071-40077

61. Tsai WT, Hsien KJ, Chang YM, Lo CC (2005) Removal of herbicide paraquat from an aqueous solution by adsorption onto spent and treated diatomaceous earth. Bioresour Technol 96:657-663

62. Draoui K, Denoyel R, Chgoura M, Rouquerol J (1999) Adsorption of Paraquat on minerals: a thermodynamic study. J Therm Anal Calorim 58:597-606 